\title{
Dissipation of Waste using Smart City Application
}

\author{
Prashant D. Shewale ${ }^{1}$, Sandeep S. Pawar ${ }^{2}$, Rekha M. Patil ${ }^{3}$ \\ Student, Information Technology, D.Y. Patil College of Engg, Ambi, Pune, India ${ }^{1,2,3}$
}

\begin{abstract}
The heart of a town depends on its purification of Air, cleanliness of the roads and highways and overall it's encompassing surroundings. However, if the condition discontinuous, then the individuals sleeps in town need to get this. Totally different sorts of Diseases detached in a plague type and it's turning into more durable to guide a healthy life. However, individuals will ignore this Condition by raising their hand to create up a healthy town. Thus we tend to make a system for group action the subject and authority during a Common platform and add along to form the capital of Bangladesh town Healthier. The combination of the sensible phone and also the web service is that the trend of the future info development and software system applications. Mobile phones square measure the foremost unremarkably used communication tools. Using mobile phones to get info isn't solely fast, however conjointly a lot of convenient route to enhance people's lives. The system is associate degree mechanical man based mostly application wherever the User himself will contribute to wash his town, apprize volunteer to come back forward or will inform town Corporation. The amenities of this application square measure - it ameliorates the user to observe close Dustbins location with path, helps to visualize on the market volunteer on the map, notify them using Google push service notification and Assists them to submit a report back to authorities if a problem arise.
\end{abstract}

Keywords: Dustbin location detection; google push service notification; clean city; Notification, Corporation officers, android.

\section{INTRODUCTION}

Air best is one of the foremost environmental and health concerns in big cities. Air pollutants are attributed to herbal or guy-made sources and might take the shape of solid particles, liquid droplets or gases. Waste pollution will increase at an alarming price all around the world that is the foremost cause of air pollution. In bangladesh, it's miles established in a speedy speed, in particular within the capital metropolis dhaka. One of the reason behind is that humans are not the usage of the dustbin in a right way and every so often the city organization is not aware enough to smooth the city. asa end result unique kinds of fitness diseases like allergies, pneumonia, asthma, and so on attacks. It is also very tough for the human beings to guide a wholesome life. The branch of environment in bangladesh and the norwegian institute for air research measured the dust awareness in dhaka metropolis for a period of 24 hours and that they observed that the end result surpassed three instances the criminal restriction.

Often we have seen that the roads, drains and dustbins aren't immaculate because of the obliviousness of the authority. For this reason, we've got designed a functionality inside the device through which humans can whinge to the city employer with right evidence and description to take some necessary steps. On this manner, proper authority could be conscious and people could get relief. this utility additionally able to provide the important facts approximately the close by police station. Once in a while felonious item or dead frame is observed within the dustbin. in this form of scenario human beings have to inform the police as early as feasible. via this utility, person can see the list of nearby police station with info and additionally able to make a call. User can also post whinge file anonymously if he observes whatever fishy and does now not need to expose his identification. a variety of people are present in our society who desires to make contributions himself for the betterment of the society or desires to use their entertainment time with the aid of engaging themselves in special social activities.

This software would be capable of combine them in a common platform. if a consumer like to work as a volunteer, can check in thru this software and immediately he may be able to look at all the volunteers in an area.

\section{MOTIVATION}

Smart town is a place wherever the standard networks and services are provided additional effectively using new digital and telecommunication technologies. However, to optimize the service provision it's necessary to higher perceive and describe the functioning of the services and additionally to get some overview regarding factors that are influencing the supply. there's a broad vary of trends or factors which will or might not play some role however even service provision additionally as economic science or politics are going to be influenced by some challenges or megatrends coming back at intervals the 21 st century. A number of these trends are already evident, to the foremost 
at hand we are able to count the population ageing or struggle for resources.

\section{LITERATURE REVIEW}

1. Using genetic algorithm for advanced municipal waste collection in Smart City:

The Internet of Things (IoT), obviously infrastructure for visualized idea of good town, brings new potentialities for the town management. IoT vision introduces promising and economical solutions for large information assortment and its analysis which may be applied in several domains and then build them operative additional with efficiency. during this paper, we are discussing one in every of the foremost difficult problems - municipal waste-collection at intervals the good town. To optimize the supplying procedure of waste collection, we tend to use own genetic rule implementation. The bestowed answer provides calculation of additional economical garbage-truck routes. As associate degree output, we offer a group of simulations targeted on mentioned space. All our algorithms enforced at intervals the integrated simulation framework that is developed as associate degree open supply answer with relevancy future modifications.

\section{Top -- k Query Based Dynamic Scheduling for IoT- enabled Smart City Waste Collection}

Smart Cities are being designed and designed for comfortable human habitation. Among services that good Cities can provide is that the environmentally-friendly waste/garbage assortment and process. During this paper, we have a tendency to inspire and propose an internet of Things (IoT) enabled system design to attain dynamic waste assortment and delivery to process plants or special garbage tips. within the past, waste assortment was treated in an exceedingly rather static manner victimisation classical research approach. As planned during this paper, nowadays, with the proliferation of sensors and actuators, still as reliable and omnipresent mobile communications, the internet of Things (IoT) allows dynamic solutions aimed toward optimizing the rubbish truck fleet size, assortment routes and prioritized waste pick-up. we have a tendency to propose a prime -- $\mathrm{k}$ question based mostly dynamic programming model to deal with the challenges of close to period of time programming driven by device information streams. Associate in Nursing humanoid app at the side of a easy GUI is developed and given so as to prove practicability and appraise a waste assortment situation victimisation experimental information. Finally, the planned models ar evaluated on artificial and real information from the town municipality of St. Petersburg, Russia. The models demonstrate consistency and correctness.

\section{Cruisers: A Public Automotive Sensing Platform for Smart Cities}

Collecting urban knowledge in an exceedingly citywide scale plays a elementary role within the analysis, development and implementation of smart cities. This demo introduces Cruisers, associate automotive sensing platform for smart cities, that is developed supported the subsequent ideas. a) Garbage assembling trucks square measure used as host vehicles to accommodate sensors, b) $3 \mathrm{G}$ cellular communication network is employed to wirelessly deliver detected knowledge on to servers, and c) Proxy server(s) are adopted to convert the format of detected knowledge to needed ones. This platform has been deployed to twenty four garbage assembling trucks at Fujisawa town, i.e., nearly $1 / 4$ of the full range of such trucks within the town. associate iOS application is additionally developed to demonstrate the sensing method and therefore the lined space

\section{Internet of Things, the Smart $X$ enabler.}

The main aim of this text is giving an image of the web of Things and its edges, even associated with the sector of energy. This may be accomplished by describing models, technologies, barriers and samples of energy consumption containment supported sensible grid and sensible cities vertical applications. Sensible grids provide vast potentialities for optimizing the energy consumption because of demand-management applications. Those quite applications will doubtless cut back the height energy usage, typically associated to the foremost expensive elements of the energy bill. for example, Datacenter operators ar very fascinated by that sort of applications as a result of they see the opportunities of cut back drastically their Capital Expenditures (CAPEX). the web of issue may bring monumental opportunities of improvement within the sensible town sector, primarily regarding the management of urban infrastructures such as: traffic flows, lighting, water systems, pickup and then on. This involves handling in real time an outsized quantity of contextspecific data yet as performing arts effective post process of historical knowledge. Public Lighting optimization, Neighborhood Services, traffic ways optimization is immediate samples of such applications within the sensible Cities field. By investment in sensible Cities comes, municipalities may improve each their financial plan and therefore the quality of the lifetime of their voters. so as to deal with such vast opportunities the ecu Commission has planned a roadmap of twelve Billion of monetary unit till 2020. during this work we tend to summarize at a look the advantages that net of issue may herald of these fields.

5 Investigation and analysis of university students' cognition and behavior of the classification and recycling

University has its special atmosphere of waste, particularly the distinctive classes of garbage and also the abnormal production of waste at special time, that makes classification and exercise of university students (CRUS) a reverse logistical issue with distinctive options. so as to check university students' knowledge and behavior of classification and exercise of university solid waste in 
Vol. 5, Issue 2, February 2017

urban center, form is meant, issued and picked up and so the info is analyzed. so data of university students' information, behavior and its factors, knowledge of classification and exercise policies may be got. moreover, some issues and policy preferences in limb area unit disclosed. These analysis results offer some policy recommendations in aspects like field atmosphere, waste transportation and sanitation facilities, responsibility mechanism and details. And these may be nice supports for the management of the reverse logistics of crus.

\section{PROPOSED SYSTEM}

Waste pollution will increase at a horrible rate everywhere the globe that is that the major explanation for pollution. In East Pakistan, it's mounted in a very fast speed, particularly within the capital town national capital. The rationale behind is that individuals aren't victimization the ashbin in a correct means and typically town corporation isn't aware enough to clean town. As a result totally different forms of health diseases like sensitivity, pneumonia, asthma, etc. attacks. It's conjointly terribly troublesome for the individuals to steer a healthy life. The Department of surroundings in East Pakistan and therefore the Norwegian Institute for Air analysis measured the dirt concentration in national capital town for a amount of twenty four hours and that they found that the result exceeded thrice the legal limit .As the population in national capital town will increase day by day, it's obtaining more durable to stay it safe and clean. Thus we tend to enforce an android primarily based application to assist individuals during this regard. Through this application, individuals would be able to observe close dustbin locations with path. This practicality can command a user to throw waste in anyplace. Usually we've got seen that the roads, drains and dustbins aren't immaculate as a result of the forgetfulness of the authority. For that reason, we've got prepended a practicality within the system through which individuals will complain to town corporation with correct proof and outline to require some necessary steps. during this means, correct authority would remember and folks would get relief. This application conjointly able to give the mandatory data concerning the close station house. typically, illegal object or natural object is found within the ashbin. during this quite state of affairs individuals need to inform the police as early as doable. Through this application, user will see the list of close station house with details and conjointly able to create a decision. User may submit complain report anonymously if he observes something funny and doesn't wish to reveal his identity

- People will contribute themselves a lot of swiftly so as to stay their town clean.

-The application provides 2 sorts of news systemvolunteer notification for facilitate and report back to authority.

-We have used OpenStreetMap to indicate the trail and points of the dustbins.
-The application provides a listing of nearby police stations and user will forthwith build a decision if required.

-A user will inform different volunteer with a detail message. Within the notification message, the volunteer will see his current position, the dustbin location and therefore the user position.

-User will see the offered volunteer in an exceedingly town corporation on OpenStreetMap.

- User will submit reports to town Corporation if he detected any wrongdoing within the management.

-User may complain to police headquarters with providing necessary data and proof through this application.

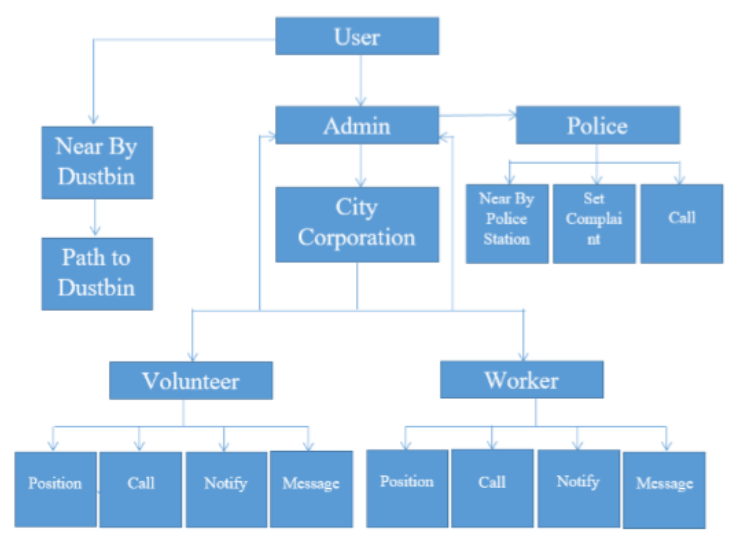

Fig 1: Architecture diagram

\section{IMPLEMENTATION}

In this application, people can contribute himself to clean his city. Through this application, user can find out nearby dustbins along path, submit complain report in City Corporation, inform the nearby police station if any kind of erroneous thing observed or can notify available volunteer in an area if needed. The home page of the application is mainly comprised of four options-

$>$ nearby dustbins

city corporation

$>$ police station

Volunteer Section

Nearby Dustbin: In this Section, users can see all the nearby dustbin in Open Street Map. We detect the nearest dustbin. After choosing 'path to go all dustbins' option, he can see the path from his current position on the map.

City Corporation: In this user can see all the users under a city corporation in OSM and there is also an option to complain. If a user thinks that the proper authority is not conscious enough to clean the dust in the city, he can submit a complaint report with proper Information and evidence. This report will be dispatched to the proper authority.

Police station: Often people found human body, illegal object, etc. in the dustbin, and sometimes people keep wastage in illegitimate ways. There may be also 


\section{IJIREEICE \\ International Journal of Innovative Research in \\ Electrical, Electronics, Instrumentation and Control Engineering \\ ISO 3297:2007 Certified \\ Vol. 5, Issue 2, February 2017}

unscrupulous use of a dustbin. For that reason, we added this section to provide necessary information about police stations. If City Corporation Doesn't Work the allocated Task to clean the garbage An Admin can send the Information to PoliceStations. Admin can see the list of nearby police station and promptly can make an emergency call to the police station. User can also lament through 'Police Complain box' section.

Volunteer Section: In 'Volunteer Section', user can see the accessible volunteer during a half on MAP. If the user register himself as a volunteer, he can produce a call, send a message or can advise others users with capturing photos exploitation go look push service notification. The volunteer are progressing to be notified instantly. once gap the notification, the volunteer can see his current position, the user WHO sends him notification and thus the wastage location. The volunteer will observe the most points of the message displayed.

\section{CONCLUSION}

We don't wish to pick out our town wasteful any longer. The Motivation of implementing this application is to form our town life superior. Because the population will increase day by day, it's turning into terribly troublesome to manage everything fleetly. Our Propounded mechanical man application will act as associate degree assistant to manage the complication. It might succor town folks to achieve consolation from waste pollution and move freely on the roads and highways. It might additionally aware the authority if any Misconduct arises and hopefully, its detection, observation and coverage practicality would facilitate town folks hereafter. Within the future, we've got an idea to feature fireplace fight and tending practicality within the application to assist country folks in vulnerable thin

\section{REFERENCES}

11] B. Valeri, M. Baez and F. Casati, "Come Along: understanding and motivating participation to social leisure activities," in Proceedings of International Conference on Cloud and Green Computing (CGC), pp.211-218, Sept. 30- Oct. 2, 213.

[2] K. Yamazaki, R. Ueda, S. Nozawa and Y. Mori, "System Integration of Daily Assistive Robot and its Application to Tidying and Cleaning Rooms," in Proceedings of International Conference on Intelligent Robots and Systems (IROS), pp. 1365-1371, 18-22 Oct. 2010.

[3] Sherman Y. T. Lang and Bing-Yung Chee, Coordination of Behaviours for Mobile Robot Floor Cleaning," in Proceedings of International Conference on Intelligent Robots and Systems, vol. 2, pp. 1236-1241, 13-17 Oct. 1998.

[4] Li Liu and Yanfang. ling, "Android City Tour Guide System Based onWeb Service," in Proceedings of Intemational Conference on Consumer Electronics, Communications and Networks (CECNet), pp. 3118-3121,21-23 April 2012.

[5] T. Zimmermann, H. Wirtz, O. Punal and K. Wehrle, "Analyzing Metropolitan-area Networking within Public Transportation Systems forSmart City Applications," in Proceedings of International Conference onNew Technologies, Mobility and Security (NTMS), pp. 1-5, Mar. 302014 - April 22014.
[6] Chen Wang, B. David and R. Chalon, "Dynamic Road Lane Management: A smart city application," In Proceedings of International Conference on Advanced Logistics and Transport (ICALT), pp 72-77,1-3 May, 2014.

[7] Wang .lie, Zhang Li, Kuang .lie and Wu Feng, "Urban Waste Managemet and Promotion of 3R in Wuhan City, China," in Proceedings of International Conference on Digital Manufaturing and Automation (ICDMA), pp. 1006 -1008, July 31 2012-Aug. 2 2012.

[8] Naveen K R \&Nandini Hampole, "Swacha Bangalore: A New Way Of. Managing Waste in Urban Areas," CCS Research Internship Papers, Centre for Civil Society, India, 2004. 